\title{
The keyword is quality not ecology
}

\author{
A. van Hal \\ Delft University of Technology, the Netherlands
}

\begin{abstract}
The Netherlands has a good reputation abroad as a country of architecture. Many people admire the architecture of famous Dutch architects such as Rem Koolhaas, MVRDV, Neutelings Riedijk and Meijer and Van Schooten. In some recent designs by members of this conceptual-oriented school of architects, several efforts have been made to become more in harmony with nature, e.g. by minimising the use of energy. Alongside this school another trend has developed over the last few years. Customer requirements have become more dominant, driven by the recent economic recession, and in many cases this has led to a more pragmatic type of architecture. This pragmatic approach, in combination with the objective for quality, has led to a new school within the Dutch architectural community. In some recent renowned designs of members of this more pragmatic school the aspect of environmental awareness is incorporated too. The architects from both schools who proved to be capable of designing so-called 'eco-architecture' could become true opinion leaders and role models and be a source of inspiration for architects who have not taken environmental awareness seriously yet. However, most architects do not want their work to be associated with green terminology such as 'eco-architecture' or 'sustainable architecture'. They would rather use language like 'smart architecture' or 'vital architecture'. Their key thrust is 'integral quality' rather than ecology. Respecting this source of motivation has shown to be critical for these frontrunners to actively contribute to increasing the ecological awareness of their architect colleagues and be opinion leaders.

Dragging them into the 'green camp' would have a contrary effect. Keywords: environmental awareness, architects, opinion leaders, integral quality, smart architecture, vital architecture, cultural creatives, styles of architecture.
\end{abstract}




\section{Introduction}

How can opinion leaders increase the ecological awareness of architects? That is the central question of this paper which is focussed on the Dutch situation. Rogers [1] states that opinion leaders are individuals who lead in influencing others' opinions about innovations. He also states that the behaviour of opinion leaders is important in determining the rate of adoption of an innovation in a system. In the case of the adoption of ecological innovations in architecture the opinion leaders will be architects. Therefore, before we can determine how they can increase the ecological awareness of architects, we must find out which architects can be considered as opinion leaders in this field. Do these architects have specific characteristics? Or do they represent a specific style?

\section{Which architects can be opinion leaders in the field of eco-architecture?}

\subsection{Characteristics}

For only a very small group of people care for the environment is leading in their decisions. According to Hoijtink [2] between 1 and 4\% of the Dutch people belong to this group. A much bigger group is formed by the so called cultural creatives. Cultural creatives are members of a subculture described for the first time by Ray [3]. This group of people longs for better health, lower consumption and more spirituality and has more respect for the earth and the diversity of life than other people. According to Ray almost $25 \%$ of the Americans is part of this growing group. Research of MarketResponse [4] shows that in the Netherlands this percentage is $15 \%$ and the number is growing too. It can be assumed that these percentages are similar for architects. This assumption is based on the fact that the group of architects for which care for the environment is leading in their work is also very small. Roughly estimated on my experiences this group of sonamed eco-architects represents between 1 and $3 \%$ of the architects. The percentage of cultural creatives amongst architects may be larger than $15 \%$ because architects are known to be more creative than most people and being creative is also one of the characteristics of cultural creatives. According to Rogers [1] opinion leaders reflect the norm of the social system. For that reason eco-architects cannot perform as opinion leaders for social creatives and other groups among architects. Based on my personal impression and the above the conclusion can be drawn that of the group of opinion leaders in Dutch architecture the ones interested in ecological innovations are quite often cultural creatives. So the forecast of Ray and MarketResponse, about the growth of the group of cultural creatives, is promising for the adoption of ecological innovations. 


\subsection{Styles of architecture}

The Netherlands has a good reputation abroad as a country of architecture. Many people admire the architecture of famous Dutch architects such as Rem Koolhaas, MVRDV, Neutelings Riedijk and Meijer and Van Schooten. The views held by this generation of conceptual oriented architects have led to numerous typical constructional innovations, such as overhangs of ten metres and folding floors. Alongside this conceptual oriented style another style, the pragmatic style, is typical for the Dutch situation and also very renowned. The economic recession has had repercussions on the architecture business. While architects in the Netherlands already have fewer final responsibilities than their counterparts abroad, most of them cannot allow their views to dominate their work. Clients have become more important now and in many cases this has led to a more pragmatic approach imbedded in an overall strive for high quality [5]. Paul de Ruiter and Hubert-Jan Henket are two internationally celebrated architects representing this pragmatic style.

Are opinion leaders in the field of eco-architecture only found within one of these two specific styles? After studying different renowned projects with integrated environmental innovations the answer to this question has to be: no. As can be seen in the different examples, described hereunder, there have been famous architects with a conceptual oriented style and architects with a more pragmatic approach that have been integrating environmental innovations in their work.

\subsubsection{Minnaert Building, Utrecht, Neutelings Riedijk Architects}

The Minnaert building houses facilities for Utrecht University's geophysics department. Half of the central hall is taken by a shallow pond. The pool plays a key part in the building's ingenious environmental control strategy. The constant accumulation of heat from computers, lights and occupants means that the building does not need heating, only the removal of heat. This is achieved by collecting rainwater and pumping it through a system of pipes into spaces that require cooling, such as laboratories.

Heated water is discharged back onto the roof, where it cools, drips back into a collection vessel and the cycle is repeated [7].

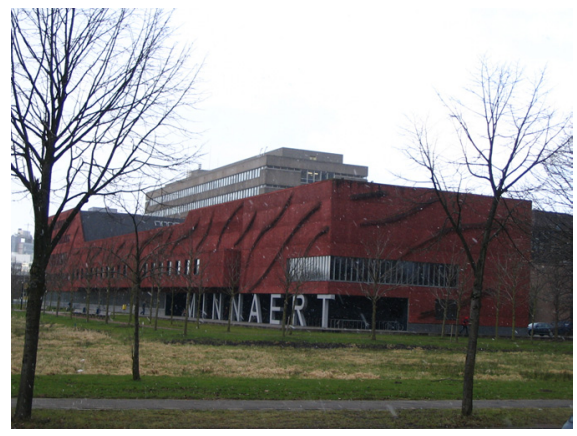

Figure 1: Minnaert Building [6]. 


\subsubsection{Posbank, Rheden, Bjarne Mastenbroek}

The tea-pavilion Posbank is designed by architect Bjarne Mastenbroek and located in the national park Velume Zoom near Rheden. Nature inspired the architect. The façades are as transparent as possible. The construction is made of beams and almost invisible bars of steel while the grass roof is part of the route through the building. The insulation is made of sheep wool and the toilets are flushed with rainwater.

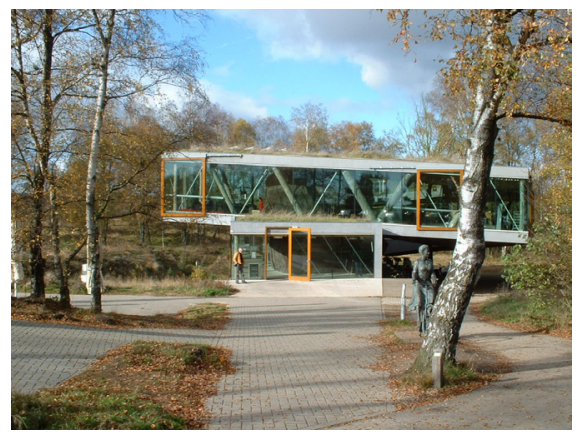

Figure 2: $\quad$ Posbank [8].

\subsubsection{ING-head office, Amsterdam, Meyer en van Schooten architects}

The building is located on the city's southern outskirts, near the A10 motorway. Key features of the building include transparency, innovation and a deep-seated respect for the environment. The transparency of the outer wall hides a second layer of glass permitting natural ventilation: not only does this protect against noise from the motorway, but it allows windows to be opened without affecting the temperature inside the building. Climate control takes advantage of the cool temperature of the ground under the building, through procedures aimed at reducing operating costs and preferring naturally cooled ventilating air. In winter the outer façade becomes a true solar panel, preserving heat within the space between the walls so that it will flow into the building when the windows are opened, while the inner façade protects against the sun's rays [10].

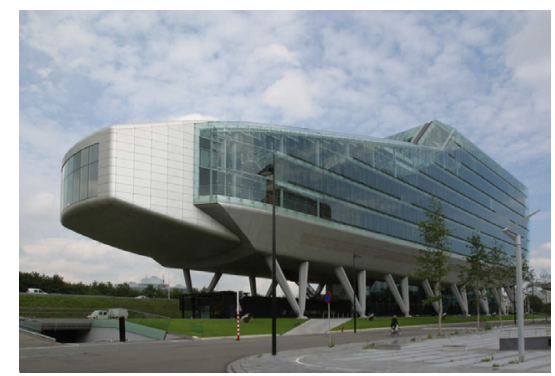

Figure 3: $\quad$ ING-head office [9]. 


\subsubsection{Governmental office Ceramique, Maastricht, Hubert-Jan Henket architects}

The separate blocks that make up the building are separated from each other by four glass solar chimneys that give the building its unique appearance. Combined with specially designed ceiling plenums, they provide natural ventilation in the offices. Outside air is extracted via self-regulating louvres above the windows, and enters the rooms under a specially designed ceiling element. As the sun heats the glass chimneybreast, air is extracted upwards and out. The office floors have a flexible layout. The atrium is part of the natural ventilation system [12].

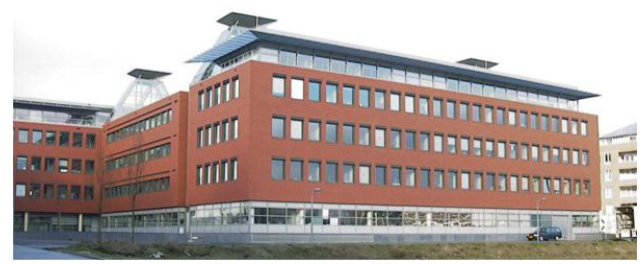

Figure 4: Governmental office Ceramique [11].

\subsubsection{GWL-terrain, Amsterdam, diverse architects}

An environmentally friendly and car-free residential area has been realized on the former site of the municipal drinking-water company (GWL) in Amsterdam. Well-known Dutch architects as Meyer and Van Schooten, Kees Christiaansen, Liesbeth v.d. Pol, Willem-Jan Neutelings and DKV demonstrated how care for the environment could be integrated in high architectural quality. Topics were energy and water efficiency, material- and waste reduction, nature and reuse of the existing buildings.

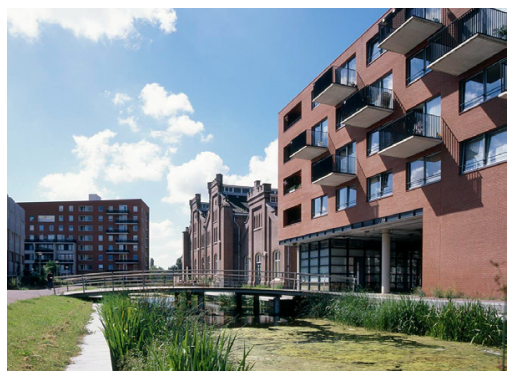

Figure 5: GWL-terrain [13].

\subsubsection{Villa Deys, Rhenen, Paul de Ruiter}

The clients wanted a practical villa in which they could live until it was impossible to live independently. They had a special wish to integrate the living program with nature. Letting the roof and side façades be clothed with plants, it looks like the three volumes were pushed out of the landscape. The lamella 
façade modules are no simple barn façades but high-tech sunscreens. The water of the swimming pool is connected to a low temperature heating system, which, combined with a heating pump, makes the system energy saving. The roof of the swimming pool is fitted with sky-lights which in combination with the reflecting quality of water makes sure that in the middle of the building a lot of daylight comes in [15].

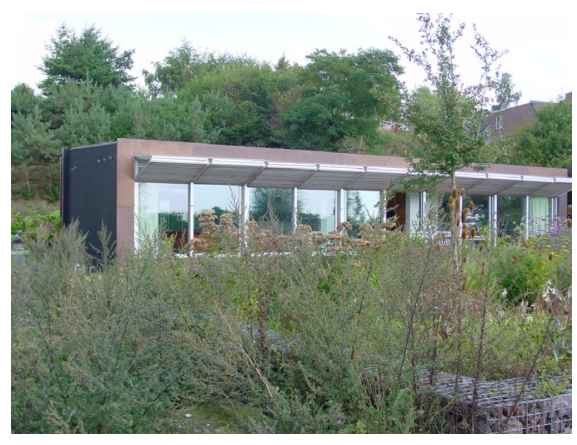

Figure 6: Villa Deys [14].

\subsection{Conclusion}

The central question in this chapter is: Which architects may be opinion leaders in the field of eco-architecture? It can be concluded that the answer is not simply found in the architectural style of their work. Their personal characteristics are of more importance. Members of the subculture cultural creatives are more likely to become opinion leaders in this field than others. Their characteristics are a longing for better health, lower consumption and more spirituality. They also have more respect for the earth and the diversity of life than most people.

Architects who have given care for the environment priority in their work, so called eco-architects, also have these characteristics but they represent only a small group of architects. For that reason it's not likely that they will be an influential source of inspiration for a large group of architects who have not taken environmental awareness seriously yet.

\section{How can opinion leaders increase the ecological awareness of architects?}

Because of the fact that care for the environment is not the main factor in their work, most well-known architects who have integrated environmental innovations in their projects, do not want their work to be associated with green terminology such as 'eco-architecture' or 'sustainable building'. For them care for the environment is only one of the aspects leading to the overall goal of quality, together with comfort, aesthetics and cost-effectiveness for example.

Fear for being dragged into the 'green camp' explains the fact that in public presentations the eco-aspect of their work is often neglected. As a result their 
work is not as effective in increasing the ecological awareness of architects as it could be.

To surmount this impasse the Royal Institute for Dutch architects (BNA) devised a new strategy and a new name for sustainable building or eco-architecture; vital architecture [16]. Similarly the Foundation for Smart Architecture presented a new approach; smart architecture [17]. Both strategies try to tackle the same problem. Will an analysis of their approaches lead to an answer on the main question of this paper?

\subsection{Vital architecture}

Vital architecture is a strategy intended to inject new élan into thinking about sustainable building, with recommendations on how to make this possible. Care for the environment is regarded as an inherent architectural quality.

The recommendations call on architects, clients, consultants and government to change the building process, to change design and to change the climate in which buildings are produced. In the context of vital architecture, the architecture must not only be environmentally sound, but resilient, dynamic and flexible in its relation between form, function and construction, at all scales and through time. Three slogans underline this aim:

Space in Time: The essence of sustainable building is thinking ahead Meaning:

- Use the present building instead of building a new one

- Use a building temporarily

- Use a temporary building

- Give the building a user manual

Time in Space: The sustainably built environment adapts cleverly Meaning:

- Ensure flexibility

- Make buildings oversized

- Make demountability possible at system and component level

- Promote prefabrication

Time and Space: Sustainable building - an interdisciplinary task

Meaning:

- Design using integrated methods

- Stimulate innovation

- Learn systematically

According to the BNA the compartmentalized legislation for sustainable building takes insufficient account of other regulations and policy. The resulting contradictions are frustrating so a new élan is required on the part of government. The existing regulations should be reconsidered.

Regarding a new élan among architects the BNA states that architects must develop a more acute feel for sustainability. They are presently good at estimating the structural and physical properties of their designs, and this skill gives them the insight they need to overstep conventional limits. In vital architecture architects must similarly develop a sensitivity towards sustainability. 
A vital design is more than the sum of its parts; it challenges the architect to selectively integrate and compose all the elements while respecting the constraints of a sustainable context. Starting right from their first design assignments, student architects must strive to cultivate this extra dimension, in which the design and the eventual built product transcends the function for which it is intended. Architects must discover the stimulus inherent in the integration of sustainability into architecture and urban planning. They must rise to the challenge of seeking new concepts that not only work well now, but are valid for the future because they are flexible, dynamic and resilient.

In their statement the BNA does not refer to the inspiring role of opinion leaders and their possibilities to stimulate this kind of architecture. But it's certain that architects will sooner discover the stimulus inherent in the integration of sustainability if architects they admire show the inspiration they get out of solving environmental problems. Designing vital architecture and propagating the inspiring challenge that goes with it can be an effective way for opinion leaders to increase the ecological awareness of architects.

\subsection{Smart architecture}

The Foundation for Smart Architecture declares smart architecture as a reaction against the pessimism that has marked 'traditional' ecological architecture ever since its emergence in the 1960's. It states: 'The traditional ecological architecture grew out of a doom-scenario of global disaster as a defensive, conservative architecture with a deep distrust of technological innovation.' Smart architecture is the opposite; an architecture that despite all the major problems brought by human dealings with the environment is still optimistic. Smart is always good and never pessimistic. Smart is airy and graceful and as a concept it is broader than just sustainability or ecology. Smart architecture is an architecture that takes up the 'green challenge' as the basis for innovation. Smart architecture is environmentally aware, not just in terms of protecting the environment but because energy and material efficiency is always smart. Smart architecture is also interactive; a smart building presents itself as an interface between its users and the surroundings. It mediates between the demands and desires of users and environment. Smart architecture is efficient, it does more with less. Smart architecture is always time based, it reacts in differing time cycles to changing user exigencies, climatological conditions, changes of function and social development. Smart architecture is 'natural', it speaks for itself, learns from nature, uses it when necessary. Smart architecture sees technology not as an enemy of nature but as a natural ally. Underneath the vision of the Foundation of Smart Architecture lies the supposition that environmental issues will radically change architecture.

Recent research [18] shows that taking up the 'green challenge' as the basis for innovation is a good way to increase the ecological awareness of architects. In that respect the work of the Foundation of Smart Architecture is very promising. Furthermore, the basis for the work of the Foundation of Smart Architecture is promoting the role of opinion leaders by describing inspiring projects and thoughts. The website and book of the foundation are filled with 
many ideas, projects and concepts, all intended as eye-openers and as sources of inspiration.

\subsection{Conclusions}

Two new strategies try to overcome the impasse in eco-architecture in the Netherlands and to increase the ecological awareness of architects. Both want to improve the image by avoiding worn-out terminology as eco and sustainable and trying to bring in new élan. The lack of ecological awareness and enthusiasm for eco-architecture among architects has a lot to do with compartmentalized frustrating legislation for sustainable building and the pessimism that marked 'traditional' ecological architecture. Opinion leaders cannot change the legislation (a task for the government) but they can introduce an optimistic approach. By declaring care for the environment as an inherent architectural quality and taking the 'green challenge' as basis for innovation in their projects, opinion leaders can stimulate other architects to integrate sustainability into architecture. 'Be smart' should be the message instead of 'be green'. And being smart is: thinking ahead, building an environment that adapts cleverly and working interdisciplinary. The keyword is quality, not ecology.

\section{Conclusions/summary}

How can opinion leaders increase the ecological awareness of architects? That was the central question of this paper which is focussed on the Dutch situation. But before we could determine how they can increase the ecological awareness of architects, we had to find out which architects can be considered as opinion leaders in this field. Do these architects have specific characteristics? Or do they represent a specific style?

It is concluded that the answer on the second question is not simply found in the architectural style of the work of opinion leaders who integrated environmental innovations in their work. Their personal characteristics are of more importance. Members of the subculture cultural creatives are more likely to become opinion leaders in this field than others. Their characteristics are a longing for better health, lower consumption and more spirituality. They also have more respect for the earth and the diversity of life than most people.

Architects who have care for the environment given priority in their work, so called eco-architects, also have these characteristics but they represent only a small group of architects. For that reason it's not likely that they will be an influential source of inspiration for a large group of architects who have not taken environmental awareness seriously yet.

How can opinion leaders increase the ecological awareness of architects? The lack of ecological awareness and enthusiasm for eco-architecture among architects has a lot to do with compartmentalized frustrating legislation for sustainable building and the pessimism that marked 'traditional' ecological architecture. Opinion leaders cannot change the legislation (a task for the government) but they can introduce an optimistic approach. By declaring care for 
the environment as an inherent architectural quality, avoiding worn-out terminology as eco and sustainable and taking the 'green challenge' as basis for innovation in their projects, opinion leaders can stimulate other architects to integrate sustainability into architecture. 'Be smart' should be the message instead of 'be green'. And being smart is: thinking ahead, building an environment that adapts cleverly and working interdisciplinary. The keyword is quality, not ecology.

\section{References}

[1] Rogers, Everett M., Diffusion of innovations, The Free Press, pp. 27, 28, 281, 1995

[2] author of Van geitenwollen sokken naar design jeans, over duurzaamheid en marketing, Kluwer, Amsterdam, 2004, interview by telephone, februari 8th, 2006

[3] Ray, Paul H. PhD, Sherry R. Anderson, The cultural creatives, How 50 million people are changing the world, Free River Press, 2000

[4] Marketresponse, www.marketresponse.nl

[5] Hal, A. van, Creativity and technology in the Netherlands, architecture, NOST network, ministry of Economic Affaires, 2005

[6] Credits figure 1: Anke van Hal, Maartensdijk

[7] Cleef, C. van, Earth Science-Utrecht University Minnaert Building, the Architectural Review, March 1999

[8] Credits figure 2: G.J. den Boon, Arnhem

[9] Credits figure 3: Joost Brouwers, Rotterdam

[10] http://www.floornature.com/worldaround/articolo.php/art78/3/en

[11] Credits figure 4: Climatic Design Consult, Nijmegen

[12] Hubert-Jan Henket architects, www.henket.nl

[13] Credits figure 5: Joost Brouwers, Rotterdam

[14] Credits figure 7: Anke van Hal, Maartensdijk

[15] www.dutcharchitects.com

[16] BNA, www.bna.nl

[17] Hinte, Ed van, Marc Neele, Jacques Vink, Piet Vollaard, Smart architecture, 010-publishers, Rotterdam 2003, www.smartarchitecture.org.

[18] Hal, A. van, Praktische Prikkels, Aanbevelingen ter vergroting van de rentabiliteit van duurzaam bouwen, SenterNovem, januari 2006 